\title{
Retinal Detachment Following YAG Laser Capsulotomy
}

\author{
C. J. MacEWEN and P. S. BAINES \\ Dundee
}

\begin{abstract}
Summary
A retrospective study of 12 patients with rhegmatogenous retinal detachment following YAG posterior capsulotomy is reported. Eleven out of these 12 were at increased risk of detachment. Three had lattice degeneration, three had previous detachment and five had axial myopia. Only $50 \%$ of the holes were typical "aphakic" post-oral breaks.
\end{abstract}

Extra-capsular extraction, currently the technique of choice in cataract surgery, has the main advantage over the previously preferred intra-capsular method of facilitating intraocular lens implantation. ${ }^{1}$ In addition it is associated with fewer posterior segment complications such as cystoid macular oedema ${ }^{2}$ and retinal detachment. ${ }^{3}$

An important disadvantage of extra-capsular surgery is opacification of the posterior capsule, resulting in reduction of visual acuity in up to $50 \%$ of cases, depending on the length of follow-up and the age of the patients studied. ${ }^{4-9}$ At present posterior capsulotomy can be carried out either by surgical discis$\operatorname{sion}^{6,7}$ or by photo-disruption using the neodymium YAG laser. ${ }^{10-17}$

Laser treatment has the advantage of being non-invasive ${ }^{11}$ and more cost effective ${ }^{18}$ than conventional surgery. There have been, however, a number of complications attributed to this technique; increased intraocular pressure, ${ }^{10,11,19-23}$ corneal endothelial damage ${ }^{19,24}$ intraocular lens pitting, ${ }^{10-13,17}$ uveitis, ${ }^{10,11,13,14}$ cystoid macular oedema ${ }^{11,13,14}$ and retinal detachment. 11,13,14,15,26-29 Retinal detachment following YAG capsulotomy occurs in up to
$2 \%$ of patients. ${ }^{26,27}$ It has been suggested that there may be a direct relationship between the two events and that retinal detachments after YAG laser are distinct from other aphakic detachments, with most patients having predisposing risk factors (myopia, lattice degeneration or previous detachment). ${ }^{26,28}$ Other studies have indicated that they are indistinguishable from other aphakic detachments. ${ }^{25,27,29}$

We therefore carried out a retrospective study of 12 patients who developed rhegmatogenous retinal detachment following YAG capsulotomy to determine the characteristics of these detachments and any predisposing risk factors.

\section{Patients and methods}

Patients who suffered retinal detachment following YAG capsulotomy were identified from the laser and theatre record books in Ninewells Hospital, Dundee and Gartnavel Hospital, Glasgow. The following information was extracted from the case notes: pre-operative refraction and axial length, time between cataract extraction and YAG capsulotomy, time between capsulotomy and 
diagnosis of retinal detachment, type and situation of the retinal hole and presence of risk factors for detachment formation.

There were 12 patients who developed unilateral rhegmatogenous retinal detachment following YAG capsulotomy. Four were male and eight female, the average age was 57 years old (range 33-77 years). Eight eyes were pseudo-phakic and four were aphakic.

\section{Results}

\section{Predisposing Factors}

Eleven out of the 12 patients in this study had a predisposition towards retinal detachment. Only one was not at increased risk (Table I).

\section{Pre-operative refraction}

The pre-operative refraction was known in 11 out of the 12 cases. Two were emmetropic and nine were myopic, four requiring a correction of six dioptres or more.

\section{Axial length}

The axial length was known in nine cases, two of the remaining three were known to be emmetropic. It was less than $25 \mathrm{~mm}$ in four cases and greater than $25 \mathrm{~mm}$ in the remaining five cases.

Retinal degeneration or previous detachment Three eyes had lattice degeneration and three patients had suffered previous detachment in the affected or fellow eye or in both eyes.

\section{Retinal Holes}

The retinal holes were equally distributed over all four quadrants of the eye. There were six large operculated tears at the equator occurring either in isolation or in association with lattice or myopic degeneration. Three

Table I Risk factors present in patients who developed retinal detachment after YAG capsulotomy

\begin{tabular}{lc}
\hline Risk factor & $\begin{array}{c}\text { Number } \\
\text { of patients }\end{array}$ \\
\hline Axial length $>25 \mathrm{~mm}$ & 5 \\
Lattice degeneration & 3 \\
Previous retinal detachment & 3 \\
None & 1 \\
Total & 12 \\
\hline
\end{tabular}

patients had small post-oral breaks and in the remainder no definite hole was identified.

\section{Time Intervals}

The mean interval between cataract extraction and YAG capsulotomy was 18.4 months (range 6-24 months) and the time from capsulotomy to the diagnosis of detachment was 6.6 months (range 0.5-18 months).

\section{Discussion}

These results indicate that in our study patients who develop retinal detachment following YAG capsulotomy were at high risk and did not conform to the stereotyped pattern of "aphakic" detachment.

Cataract surgery of any type increases the chances of subsequent retinal detachment, but maintenance of an intact posterior capsule helps to minimise this complication. ${ }^{3,30}$ The rate of detachment after intra-capsular surgery is approximately $3.5 \% 3,31$ whereas it is much less $(1 \%)$ after uncomplicated extracapsular surgery ${ }^{30,32}$ and $2 \%$ following capsulotomy. ${ }^{26,27}$ Photo-disruption by the YAG laser may precipitate detachment by causing vitreous liquification, direct retinal damage or setting up pressure wave transients..$^{25,27,29,33}$ There are certain conditions-myopia, lattice degeneration and previous retinal detachment-which pre-dispose to the development of detachment in all eyes, whether phakic or aphakic. ${ }^{34-36}$ Retinal detachment following YAG capsulotomy may therefore be a consequence of:

(a) the cataract extraction itself.

(b) the opening in the posterior capsule.

(c) damage directly caused by the laser.

(d) any predisposing retinal lesion.

Regarding the first two possibilities, both mechanical and biochemical factors have been implicated in the development of detachments following intra-capsular surgery. Herniation of the vitreous into the anterior chamber which leads to posterior vitreous detachment and increased mechanical traction on the vitreous base with subsequent retinal hole formation is one postulated mechanism regarding the aetiology of aphakic detachment. ${ }^{37}$ Biochemically, the hyaluronic acid content of the vitreous in aphakic eyes has been shown to be reduced compared with 
that of phakic eyes due to loss of the physical barrier between the anterior and posterior segments. ${ }^{38}$ This may be responsible for an increased rate of vitreous liquifaction and syneresis with subsequent development of retinal tears.

However, the size of the YAG capsulotomy is relatively small. Also, the presence of an intra-ocular lens and peripheral capsule prevent much forward movement of the vitreous and act as a barrier against biochemical changes, making the above factors unlikely.

In addition, because the detachments occur so soon after use of the YAG, some authors suspect that the laser itself is responsible for retinal hole formation. Direct damage to the retina by the laser has been reported, but only when the beam is focused at a distance of two to three millimetres from the retinal surface. ${ }^{39}$ This is considerably closer than occurs during posterior capsulotomy. None of the retinal holes were accompanied by haemorrhage or retinal pigment epithelial abnormalities as would be expected if they had been caused directly by laser damage. Transient acoustic shock waves are set up at the formation and again at the collapse of the plasma. ${ }^{33}$ These have been shown to produce pressure effects which radiate quite a distance into the eye and may cause shearing forces on the peripheral retina. ${ }^{33}$ Rupture of the anterior hyaloid face and damage to the vitreous directly behind the posterior capsule occurs during capsulotomy ${ }^{25}$ and this may predispose to retinal hole formation.

The rate of retinal detachment following YAG capsulotomy is similar to that following surgical discission..$^{10,40,41}$ This suggests that it is not the technique of making the capsulotomy which is important, but rather it's presence.

The ease with which capsulotomy can be carried out using the YAG has led some to believe that it may be employed at an earlier stage than surgery, and that this intervention soon after the original surgery may increase the complication rate. ${ }^{10}$ Were found that the time between cataract surgery and YAG capsulotomy was relatively short, but feel that the time interval between the laser application and development of the detachment is of more importance.

Eleven out of our 12 patients had risk factors for the development of retinal detachment. Myopia, lattice degeneration and previous retinal detachment are all recognised as increasing the chance of developing of retinal detachment. ${ }^{34-36}$ In myopia it is, however, not the refractive error, per se, which is important, but the axial length of the eye. Eyes with an axial length of 25 millimetres or more are at increased risk of developing retinal detachment after cataract extraction. ${ }^{42}$ Although previous studies regarding retinal detachment after YAG capsulotomy have indicated that the patients were at increased risk because of myopia, ${ }^{15,26,28}$ these were based on pre-operative refraction, which may include a degree of index myopic changes associated with the lens opacities. We included axial length measurements in this study in order to ensure that all cases of index myopia were recognised and found that almost half of our patients had significant axial myopia.

Small post-oral breaks are typically found in aphakic retinal detachments, whereas large equatorial tears are more suggestive of myopic detachments. ${ }^{43} \mathrm{We}$ found that $50 \%$ of our cases had tears which were not typically "aphakic", but were not more likely to be associated with lattice or myopia which have equatorial pathology. The remaining holes were more typical of aphakic detachments (retinal holes often not being found in aphakic patients as they are small and very peripheral; these may be especially difficult to see in cases where there is an opaque posterior capsule). Previous work has found that all, or most, of the holes in patients with post YAG detachments were in the post-oral region, ${ }^{26,27}$ and that the features of these detachments were typically aphakic.

An important factor linking the YAG capsulotomy with the detachment is the short time interval between the two events. ${ }^{25}$ The average time between intra-capsular lens extraction and aphakic detachment is three years, ${ }^{3,45}$ compared with six months between YAG capsulotomy and detachment. ${ }^{25,27-29}$ However the aphakic patients have usually been followed up over a longer time interval. The follow-up after YAG capsulotomy is, in general, short. ${ }^{26-29}$ Almost $50 \%$ of the aphakic detachments occurred in the first year after cataract extraction ${ }^{3,43-46}$ and these were in 
patients at high risk or who had vitreous complications. The rate of aphakic detachment continued to rise with prolonged follow-up. The YAG laser is a relatively novel mode of treatment, only having been in general use in Scotland over the past two years, and we may be reporting on these patients a little prematurely. Longer follow up is necessary in order to see the whole picture. The nature of these detachments may change with time, becoming more similar to aphakic ones.

Hopefully, however, the incidence will be less because the relatively small hole in the posterior capsule and the presence of an intraocular lens may reduce the degree of vitreous prolapse and molecular flux into the anterior chamber, thus reducing any adverse mechanical and biochemical changes in the vitreous. Also, as this procedure is non invasive it cannot be accompanied by vitreous loss, a complication of intra-capsular surgery which increases the incidence of post operative macular oedema and retinal detachment. ${ }^{44}$ Thirdly, the suspensory ligaments of the zonule remains intact at the ora because the peripheral capsule is left undisturbed during extra-capsular surgery and capsulotomy. This should reduce the number of tears in this post oral region. ${ }^{46}$

We have found that after a short follow up, more than $90 \%$ of our patients who developed rhegmatogenous retinal detachment after YAG capsulotomy had an underlying predisposition to retinal detachment. These patients all presented within a short time of the capsulotomy and we therefore recommend that all patients should have a full fundal examination both pre- and post-YAG laser treatment. This should be detailed, with scleral indentation and/or three mirror examination in patients at high risk as one would have done prior to intra-capsular surgery. Treatment should be considered for predisposing lesions and patients should be warned of the risks and symptoms of detachment in order that they can present early for prompt assessment and treatment.

We would like to thank Drs T. Barrie and C.G. MacEwan for allowing us to include their patients in this study.

\section{References}

${ }^{1}$ Fagadau FR, Maumenee AE, Stark WJ, Datiles M: Posterior chamber intra-ocular lenses at the Wilmer Institute; A comparative analysis of complications and visual results. $\mathrm{Br} \mathrm{J}$ Ophthalmol 1984, 68: 13-18.

2 Jaffe NS, Lindscombe SM, Clayman HM, Gass JD: A fluorescein angiographic study of cystoid macular edema. Am J Ophthalmol 1981, 92: 775-7.

${ }^{3}$ Percival SPB, Anand V, Das SK: Prevalence of aphakic retinal detachment. $\mathrm{Br} J$ Ophthalmol 1983, 67: 43-5.

${ }^{4}$ Pearce JL: Modern Extracapsular surgery. Trans Ophthalmol Soc UK 1979, 99: 176-82.

${ }^{5}$ Emery JM, Wilhelmus KA, Rosenberg S: Complications of phacoemulsification. Ophthalmology 1978, 85: 141-50.

6 Wilhelmus KA and Emery JM: Posterior capsule opacification following phacoemulsification. Ophthalmic Surg 1980, 11: 264-7.

${ }^{7}$ Lindstrom RL and Harris WS: Management of the posterior capsule following posterior chamber lens implantation. Am Intra-ocular Implant Soc J 1980, 6: 255-8.

${ }^{8}$ Sinskey RM and Cain W: The posterior capsule and phacoemulsification. Am Intra-ocular Implant Soc J 1978, 5: 206-7.

${ }^{9}$ Seward HC and Doran RML: Posterior capsulotomy and retinal detachment following extracapsular lens surgery. Br J Ophthalmol 1984, 68: 37982.

${ }^{10}$ Harris WS, Herman WK, Fagadau WR: Management of the posterior capsule before and after the YAG laser. Trans Ophthalmol Soc UK 1985, 104: 533-5.

${ }^{11}$ Aron-Rosa D, Aron JJ, Griesman M, Thyzel R: Use of the neodymium-YAG laser to open the posterior capsule after lens implant surgery: A preliminary report. Am Intra-ocular Implant Soc J 1980, 6: 552-4.

12 Gardner KM, Straatsma BR, Pettit TH: Neodymium-YAG laser capsulotomy. The first 100 cases at UCLA. Ophthalmic Surg 1985, 16: 24-8.

${ }^{13}$ Aron-Rosa D, Aron JJ, Cohn HC: Use of a pulsed picosecond Nd-YAG laser in 6,664 cases. Am Intra-ocular Implant Soc J 1984, 10: 35-9.

${ }^{14}$ Chambless WS: Neodymium-YAG laser posterior capsulotomy results and complications. Am Intraocular Implant Soc J 1985, 11: 31-2.

15 Terry AC, Stark WJ, Maumenee AE, Fagadau W: Neodymium-YAG laser for posterior capsulotomy. Am Intra-ocular Implant Soc J 1983, 96: 716-20.

${ }^{16}$ Fankhauser F, Lortscher H, Van der Zypen E: Clinical studies on high and low power laser radiation upon some structures of the anterior and posterior segments of the Eye. Int Ophthalmol 1982, 5: $15-32$.

17 Jagger JD, Marshall J, Hamilton AM: NeodymiumYAG laser in ophthalmic practice-principles and early experience. Trans Ophthalmol Soc UK 1985, 104: 181-90.

${ }^{18}$ MacEwen CJ and Dutton GN: Neodymium-YAG 
laser in the management of posterior capsular opacification-complications and current trends. Trans Ophthalmol Soc UK 1986, 105: 337-44.

${ }^{19}$ Kraff MC, Sanders DR, Lieberman HL: Intraocular pressure and the corneal endothelium after neodymium YAG laser posterior capsulotomy. Arch Ophthalmol 1985, 103: 511-14.

${ }^{20}$ Channel MM and Beckman M: Intra-ocular pressure changes after neodymium-YAG laser Posterior capsulotomy. Arch Ophthalmol 1984, 102: 1024-6.

${ }^{21}$ Shrader CE, Belcher CD, Thomas JV, Simmons RJ: Acute glaucoma following Nd-YAG laser membranotomy. Ophthalmic Surg 1983, 14: 1017-18.

22 Vine AK: Ocular hypertension following Nd-YAG laser capsulotomy: a potentially blinding complication. Ophthalmic Surg 1984, 15: 283-4.

${ }^{23}$ Parker MD, Clorfeine GS, Stoklin RD: Marked intra-ocular pressure rise following $\mathrm{Nd}-\mathrm{YAG}$ laser capsulotomy. Ophthalmic Surg 1984, 15: 103-4.

${ }^{24}$ Kerr-Muir MG and Sherrard ES: Damage to the corneal endothelium during Nd-YAG photodisruption. Br J Ophthalmol 1985, 69: 77-85.

${ }^{25}$ Fastenberg DM, Schwartz PL, Lin HZ: Retinal detachment following neodymium-YAG laser capsulotomy. Am J Ophthalmol 1984, 97: 288-91.

${ }^{26}$ Ficker LA, Vickers S, Capon MRC, Mellerio J, Cooling RJ: Retinal detachment following Nd: YAG posterior capsulotomy. Eye 1987, 1: 86-9.

${ }^{27}$ Ober RR, Wilkinson CP, Fiore JV, Maggiano JM: Rhegmatogenous retinal detachment after neodymium-YAG laser capsulotomy in phakic and pseudophaki eyes. Am J Ophthalmol 1986, 101: 81-9.

${ }^{28}$ Leff SR, Welch JC, Tasman W: Rhegmatogenous retinal detachment after YAG laser posterior capsulotomy. Ophthalmology 1987, 94: 1222-5.

${ }^{29}$ Winslow RL and Taylor BC: Retinal complications following YAG laser capsulotomy. Ophthalmology 1985, 92: 785-9.

${ }^{30}$ Percival SPB: Long term complications from extracapsular cataract surgery. Trans Ophthalmol Soc UK 1985, 104: 915-18.

${ }^{31}$ Norton EWD: Retinal detachment in aphakia. Am J Ophthalmol 1964, 58: 111-24.

32 Coonan P, Fung WE, Webster et al: The incidence of retinal detachment following extra-capsular extraction: a ten year study. Ophthalmology 1985 92: 1096-101.

${ }^{33}$ Vogel A, Hentschel W, Holtzfuss J, Lauterborn W: Cavitation bubble dynamics and acoustic transient generation in ocular surgery with pulsed neodynium-YAG lasers. Ophthalmology 1986 , 93: $1259-69$.

${ }^{34}$ Vitreo-retinal disorders. Tolentino, Schepens Freeman (eds). Diagnosis and management. WB Saunders Co., Philadelphia 1976. Chapters 15 \& 16.

${ }^{35}$ Hyams SW, Bialik M, Neumann E: MyopiaAphakia. Prevalence of retinal detachment. $\mathrm{Br} J$ Ophthalmol 1975, 54: 480-2.

${ }^{36}$ Morse PH: Lattice degeneration of the retina and retinal detachment. Am J Ophthalmol 1974, 78: 930-4.

${ }^{37}$ Wadsworth JAC: Forward shift of the vitreous following cataract surgery; it's treatment. Highlights Ophthalmol 1972, 13: 70-84.

${ }^{38}$ Osterlin S: Changes in the macromolecular composition of the vitreous produced by removal of the lens. Concilium Ophthalmologicum, 21st, 1970, Mexico, 1971, 222: 1620-3.

${ }^{39}$ Jampol LM, Goldberg MF, Jednock N: Retinal damage from a Q-switched YAG laser. Am J Ophthalmol 1983, 96: 326-9.

${ }^{40}$ Knolle GE: Knife versus neodymium-YAG laser capsulotomy: a one-year follow-up. Am Intraocular Implant Soc J 1985, 2: 448-55.

${ }^{41}$ Liesegang TJ, Bourne WM, Ilstrup DM: Secondary surgical and neodymium-YAG laser discissions. Am J Ophthalmol 1985, 100: 510-19.

${ }^{42}$ Clayman HM, Jaffe NS, Light DS, Jaffe MS, Cassady JC: Intra-ocular lenses, axial length and retinal detachment. Am J Ophthalmol 1981, 92: 77880.

${ }^{43}$ Schepens CL: Retinal detachment and aphakia. Arch Ophthalmol 1951, 45: 1-16.

${ }^{44}$ Le Mesurier R, Vickers S, Booth-Mason S, Chignell AH: Aphakic retinal detachment. Br J Ophthalmol 1985, 69: 737-41.

${ }^{45}$ Ashratzadeh M, Schepens CL, Elzenemy I. et al: Aphakic and phakic retinal detachment. 1. Pre-op findings. Arch Ophthalmol 1973, 89: 47683.

46 Phillips CI: Distribution of breaks in aphakic and "senile" eyes with retinal detachments. $\mathrm{Br} J$ Ophthalmol 1963, 47: 744-52. 